\title{
U.S. Geological Survey Science in Support of the North American Bat Monitoring Program (NABat)
}

$\mathcal{N}$ orth American bats face increasing threats to their populations. The bat fungal disease white-nose syndrome (WNS) has killed more than 6 million bats of many different species since it emerged in 2007 , and it now spans the continent. Rapid human and natural landscape changes also threaten certain bats, such as wind turbines that pose a physical threat to bats and habitat loss and fragmentation. Because bats are extremely secretive and fly only at night, the distributions and abundances of North America's many bat species are not yet well understood.

The North American Bat Monitoring Program (NABat) was established in 2015 to acquire the information needed to help conserve and manage bat populations across North America. NABat uses standardized survey data to track the 47 species of bats found throughout the United States, Canada, and Mexico. This
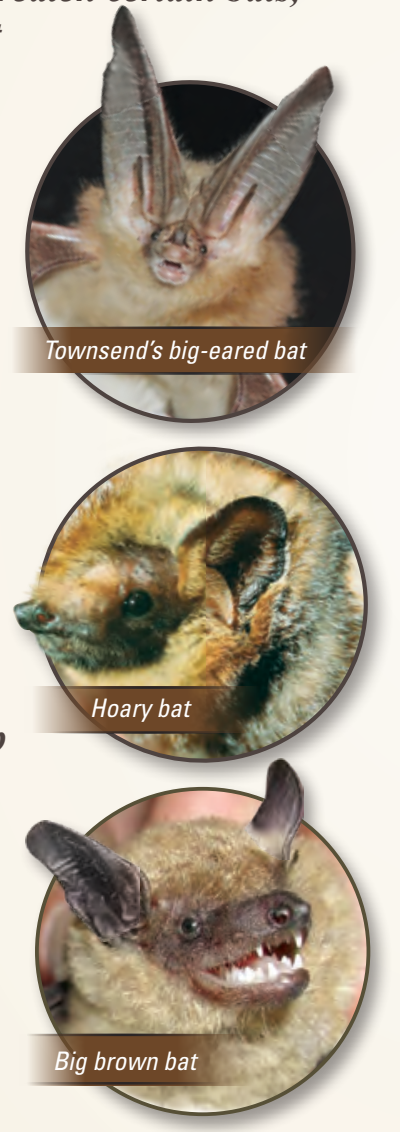
multinational, multiagency coordinated research and monitoring program is designed to assess populations of North American bats at local, State, and range-wide scales. This information is helping resource managers detect early signs of population declines, estimate extinction risk, establish conservation priorities, and evaluate the effectiveness of management actions.
Importance of bats - Bats make up one-fifth of all mammalian species worldwide and are found on every continent except Antarctica. They contribute to overall ecosystem health by suppressing pest insects and pollinating plants and spreading seeds. Bats likely save farmers billions of dollars each year in the United States and other parts of the world by being the main predators of many night-flying insect pests (Boyles and others, 2011).

Eight North American bat species are listed as federally endangered or threatened, and more than one-half are of current conservation concern in the United States, Canada, or Mexico. The eight bat species are Florida bonneted bat (Eumops floridanus); gray bat (Myotis grisescens); Hawaiian hoary bat (Lasiurus cinereus semotus); Indiana bat (Myotis sodalis); Mexican long-nosed bat (Leptonycteris nivalis); northern long-eared bat (Myotis septentrionalis); Ozark big-eared bat (Corynorhinus townsendii ingens); and Virginia big-eared bat (Corynorhinus townsendii virginianus).

The U.S. Geological Survey (USGS) leads, manages, and coordinates the multinational North American Bat Monitoring Program (NABat) as well as conducts scientific research on bats. Specifically, the USGS-

- Develops platforms to support common standards and monitoring protocols for data collection, management, validation, curation, and delivery.

- Researches and develops statistical models and other management tools that are focused on processing and interpreting acoustic monitoring data and colony count data.

- Provides integration with the WNS surveillance and diagnostic tracking database to improve early detection, risk assessment, surveillance, and control of WNS.

- Creates a nexus of multinational communication and coordination for North American bat monitoring.

USGS and NABat partners help resource managers and policymakers make informed decisions regarding the conservation of bats across North America. USGS science also helps inform decision making with respect to WNS surveillance and bat vulnerability; mitigation of potential impacts of energy development on bats; prelisting conservation efforts for regulatory agencies; and land management practices. 


\section{Featured NABat Projects and Tools}

USGS scientists use data collected by NABat partners to develop robust tools and platforms that assist in conservation and management of bats across North America. These include-

\section{Acoustic Surveys, Distribution Maps, Range Expansions}

Bats avoid obstacles and find insect prey in the dark by calling nearly continuously, at a higher pitch than humans can hear, and then listening to the echoes. By recording and analyzing these high-frequency echolocation calls, scientists are able to conduct acoustic surveys, develop species distribution maps, and document potential range expansions and new species occurrences. Acoustic surveys also assist managers in establishing baseline data as WNS begins to affect bat populations across the United States.

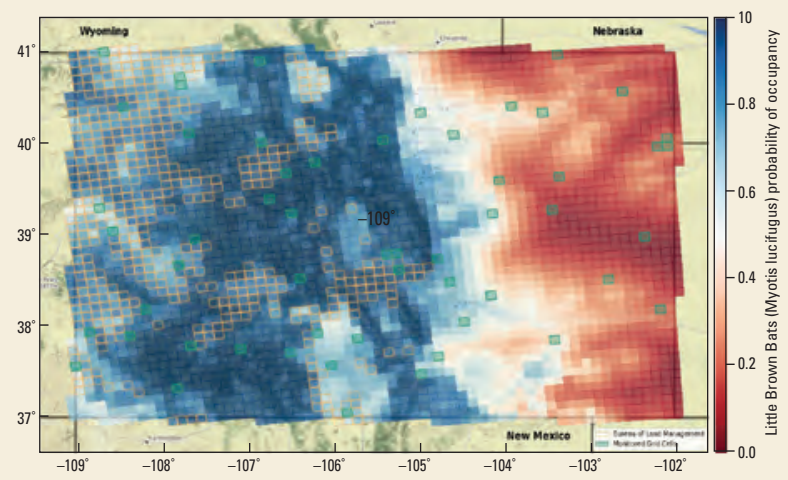

This map was developed by the U.S. Geological Survey using data from bats calls recorded throughout Colorado and shows the probability of finding little brown bats throughout the State (blue=higher probability, red=lower probability of occurrence). Scientists and wildlife managers can use these maps to track species distributions and assess population status prior to the arrival of white-nose syndrome or other threats (Irvine and others, 2020).

\section{Colony Count Analysis and White-Nose Syndrome Surveillance}

In the parts of the United States where large aggregations of bats occur in caves, surveys at winter and summer bat colonies are being conducted to assess species distribution and local abundance. These survey data help in assessing the geographic patterns and ecological drivers of colony size, hibernation behavior, and habitat associations for hibernating bat species. The data also enable the development of models to predict the regions and species most at risk to WNS as well as target management actions and surveillance efforts.

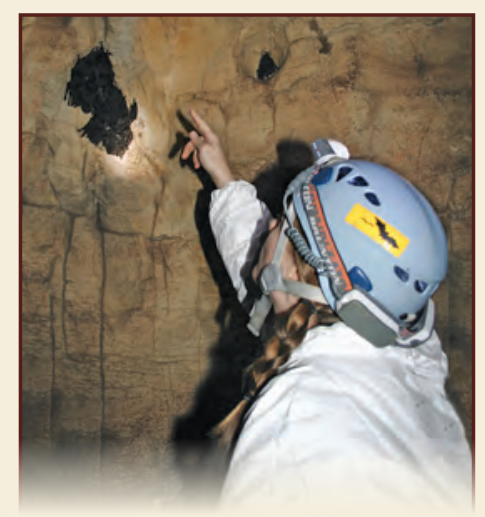

Kentucky Department of Fish and Wildlife Resources bat ecologist counts bats. Photograph by Ann Froschauer/U.S. Fish and Wildlife Service.

\section{NABat Partner Portal}

The NABat Partner Portal provides a "one-stop shop" for accessing guidance documents and resources. The portal also provides NABat partners with access to information about NABat projects through an interactive map and database. Anyone who is interested in sharing bat monitoring data can do so through the NABat Partner Portal (https://sciencebase.usgs.gov/nabat/\#/home/).
NABat partners who contributed data during 2019:

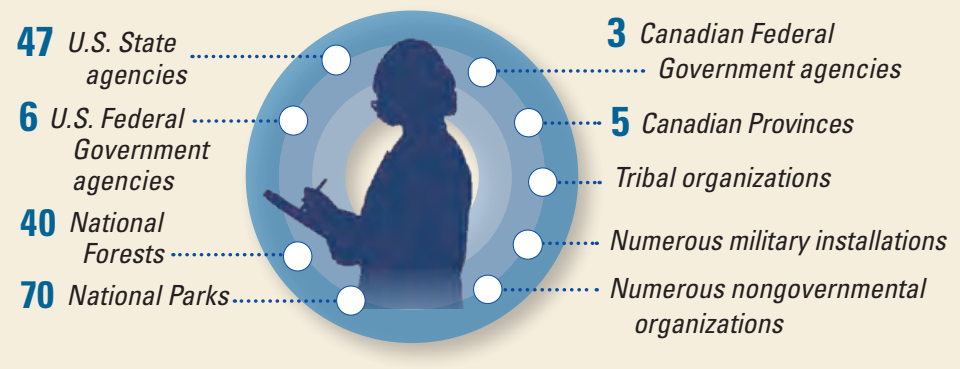

\section{Reliance on NABat Partnerships}

Partners are essential to the success of NABat. The data contributed by NABat partners provide baseline knowledge on the distribution and abundance of bats, which is used to evaluate the impacts of the threats to bats across North America. These data are also the foundation for the scientific information used to set conservation priorities and evaluate the effectiveness of management actions. Therefore, the data contributed by NABat partners are invaluable.

NABat partners contribute data through the NABat Partner Portal. Partners are encouraged to contribute not only new data but also compatible legacy data (collected prior to the establishment of NABat) and found data (collected outside the formal survey design). NABat scientists will integrate these data into species' status and trend assessments.

Become a NABat partner and start monitoring! Go to https://sciencebase.usgs.gov/nabat/\#/home/and select "Request an Account" in the upper right-hand corner of the page to get started.

\section{References Cited}

Boyles, J.G., Cryan, P.M., McCracken, G.F., and Kunz, T.H., 2011, Economic importance of bats in agriculture: Science, v. 332, no. 6025, p. 41-42, accessed January 22, 2020, at https://doi.org/10.1126/science.1201366.

Irvine, K.M., Wright, W.J., Litt, A.R., and Reichert, B.E., 2020, Bat occupancy model predictions for Colorado, acoustic data from 2016-2017: U.S. Geological Survey data release, accessed February 20, 2020, at https://doi.org/10.5066/P9LXCYC4.

\section{By Brian E. Reichert and Suzanna C. Soileau}

For more information on the NABat program, contact: Brian Reichert, NABat Program Coordinator

Email: breichert@usgs.gov / Telephone: 970-226-9245

Or visit the North American Bat Monitoring Program (NABat) website at https://www.nabatmonitoring.org/.

Photograph credits, page 1: Top banner-Little brown bats (Myotis lucifugus) in a New York cave (Nancy Heaslip, New York State Department of Environmental Conservation). Bat collage - Some endangered bat species (from top to bottom, Ann Froschauer/U.S. Fish and Wildlife Service; Frank Bonaccorso/USGS; Gabe Reyes/USGS, Western Ecological Research Center). Bottom banner-NABat partners perform acoustic surveys (USGS).

Publishing support provided by the U.S. Geological Survey, Science Publishing Network, Reston and Tacoma Publishing Service Centers.

Design: William Gibbs

ISSN 2327-6916 (print) ISSN 2327-6932 (online) https://doi.org/10.3133/fs20203008 